\title{
Book Review: Methods in Karst Hydrogeology, Nico Goldscheider and David Drew (eds)
}

Taylor \& Francis, 2007

\author{
Paul W. Williams
}

Keywords Reviews (book) · Karst · Hydrogeology

The book is an introduction to the methods that can be applied to the study and exploitation of karst aquifer systems. It is aimed at postgraduate students, practitioners, and senior scientists. The book authors are an international team of 21 karst specialists - both scientists and practitioners - from eight countries in Europe and North America. Their work is presented in 11 chapters: Introduction, The geological and geomorphological framework, Speleological investigations, Hydrological methods, Hydraulic methods, Hydrochemical methods, Isotopic methods, Tracer techniques, Geophysical methods, Modelling karst hydrodynamics, and Combined use of methods. No chapter deals explicitly with the management of water resources, although various aspects of it are encountered in several chapters; for example, the identification of contaminant sources in chapter 6 , and the assessment of water quality, contaminant problems, and groundwater vulnerability in chapter 11. Engineering considerations are not dealt with specifically, because of their coverage elsewhere.

The book outlines why karst aquifers require specific investigation techniques, and then goes on to explain the methods that can be used to study and understand them.

Received: 2 September 2008 / Accepted: 23 October 2008

Published online: 27 November 2008

Many of the methods explained are standard hydrological techniques such as precipitation monitoring, stream flow measurement and borehole testing, while others such as water tracing, are especially applicable to karst. The methods described can be used for a wide range of applications, from scientific studies to water resources investigations.

A major advantage of a multi-author book such as this is that specialists and active practitioners convey and share their experience and the benefit of up-to-date knowledge. Consequently the references cited, the techniques explained, and the examples used are absolutely up-to-date. The discussion of the application to karst of the isotopic, tracer and geophysical techniques is particularly interesting and useful. And the chapter on modelling karst hydrodynamics is one of the best concise statements on this difficult and important topic to be found in the literature.

A major disadvantage of a book of essays around a topic is usually that the various authors do not achieve the same level in their writing but this is not a significant problem with this book. It is written throughout at a level appropriate for the advanced student and practising hydrogeologist. However, the book does not have an obvious conceptual framework or organising theme to guide its structure and approach, although the topics covered are in an appropriate logical sequence. Hence the volume is not a textbook, but a valuable work of reference on the latest ideas in karst hydrogeology. It should be in every serious science library.

(C) Springer-Verlag 2008

P. W. Williams $(\square)$

School of Geography, Geology \& Environmental Science, Auckland University,

PB 92019, Auckland, New Zealand

e-mail: p.williams@auckland.ac.nz

\section{References}

Goldscheider N, Drew D (eds) (2007) Methods in Karst Hydrogeology. International Contributions to Hydrogeology 26, International Association of Hydrogeologists, Taylor \& Francis, London, 264 pp. ISBN 978-0-415-42873-6 